\title{
Econometric TFP Targets, Incentive Regulation and the Ontario Gas Distribution Industry
}

\author{
MARK N. LOWRY \\ Pacific Economics Group Research \\ LULLIT GETACHEW* \\ Pacific Economics Group Research
}

\begin{abstract}
We present a price cap mechanism, which features an external standard, constructed to elicit efficient utility performance. We focus on a method for setting the external standard, which is usually based on industry total factor productivity (TFP), when 'peer' data are not readily available. The procedure is based on an econometric cost model and externalizes the performance target or TFP by using a combination of industry and individual utility data. To highlight the importance of the method, we profile the approach that was considered and partly adopted in the current incentive regulation plan of Ontario's gas distribution industry.
\end{abstract}

\section{Introduction}

In this paper we present a method for calculating productivity for use in an incentive regulatory (IR) plan. This approach was considered in the recently approved gas regulatory plan of Ontario, Canada. The rates approved for the two major gas utilities, Enbridge and Union Gas, by the Ontario Energy Board (OEB) are for the five year regulatory period of 2008-2012. The final plan for Union Gas that the OEB approved, in January 2008, ${ }^{1}$ is largely based on the productivity measurement that we feature in the paper.

The use of productivity measures is characteristic of North American price cap IR plans. Lowry and Kaufmann (2002) detail the nature and evolution of North American price cap plans, and provide a rich set of examples of where and how they have been implemented. $^{2}$ The North American price cap IR approach, like the alternative British approach, sets the initial level for regulated rates (also known as the 'P0') in a regulatory

\footnotetext{
* Contact Author. Pacific Economics Group Research, 22 E. Mifflin Street, Madison, WI 53703. E-mail: lgetachew@earthlink.net. We appreciate the helpful comments of two anonymous referees.

${ }^{1}$ Ontario Energy Board. 2008. In the Matter of an Application by Union Gas Limited for an Order or Orders approving or fixing a multiyear incentive rate mechanism to determine rates for the regulated distribution, transmission and storage of natural gas, effective January 1, 2008. Decision EB-2007-0606.

${ }^{2}$ The CPI-X rate escalation mechanism is one of the cornerstones of incentive regulation plans. As Joskow (2007), however, indicates other incentive mechanisms, such as rate freezes and moratoria, are also in use in the US utility industries. The North American approach we mention throughout the paper refers to indexed price cap plans.
} 
process known as a rate case. Between rate cases the regulated rates are escalated annually at a rate which reflects the difference between inflation and an $\mathrm{X}$ factor. In the North American approach, the $\mathrm{X}$ factor is designed to reflect industry productivity growth while in the British approach it reflects projected costs. In particular, total factor productivity (TFP) growth is used to determine the $\mathrm{X}$ factor in CPI-X price cap schemes in North American price cap plans. ${ }^{3}$ We develop the details of the North American price cap IR mechanism in Section 2.

Typically, a key design objective in the North American price cap approach to rate setting is to ensure that the parameters of the regulatory mechanism reflect conditions that are external to a given utility in order to incent it to provide efficient service. Thus, one of the major considerations in implementing this approach - the calculation of TFP growth must be based on data external to each utility that is subject to incentive regulation. Ordinarily industry-wide data is used for this purpose. However, at times there may not be sufficient peers to develop good productivity targets for all companies. Suppose, for example, that there are two gas distributors in a country and that one faces slow customer growth and the other faces rapid customer growth. Their prospects for TFP growth are then very different. In addition, the data required for TFP calculation such as the decomposition of capital cost into accurate price and quantity indexes are sometimes unavailable. In the particular case of the Ontario gas distributors there was no readily available Canadian gas industry data to calculate appropriate industry TFP. Further, the operating conditions of the Ontario distributors are sufficiently different from the neighbouring US gas distributors, which prevented the use of these data to calculate TFP. In such situations, TFP targets are difficult to establish.

There exists an alternative econometric approach to TFP computation that can be used to set the TFP targets in this case. It uses a good combination of industry information and utility data that externalize the TFP targets and are appropriate for this situation. Further, this approach provides an alternative to the index based productivity measurement used in the North American rate setting mechanism. ${ }^{4}$ We present this approach in Section 3 .

The proposed methodology draws elasticity estimates from a total cost function to fit a TFP growth formula drawn from mathematical theory. The United States is the ideal source of data for the total cost function research because the requisite capital cost data are available. US data are also distinguished by their generally high quality and for the accessibility of varied business conditions data that LDCs face. Using these, we illustrate the development of productivity estimates that are still external in nature in circumstances where there are insufficient peers and data to allow the computation of relevant industry TFP indexes useful for the type of incentive regulation that is the focus here. Our work thus provides a very important methodology for computing TFP growth targets for incentive regulation that has not been used previously in a regulatory setting or proposed for this use in the energy economics literature.

\footnotetext{
${ }^{3}$ Some plans of this type do use industry specific input price indexes that properly reflect the cost impact of a surge in, say, copper prices. Most plans, however, use macroeconomic price measures such as the gross domestic product price index. A "stretch" factor is often added to the X factor and this may reflect the results of a benchmarking exercise. In principle, the regulator is free to raise Po and lower the stretch factor or vice versa. In practice, the productivity target remains an important parameter to be determined.

${ }^{4}$ See Diewert (1981) for indexing methods used to compute TFP.
} 
We discuss the US and the two Canadian gas distributors' data used in the empirical work in Section 4. In Section 5, we present the econometric model and its parameter estimates employed to obtain the TFP targets. In Section 6, we apply the parameters from the econometric model to calculate the TFP projection considered in the incentive rate plan approved for Union Gas. Finally, we provide brief concluding remarks in Section 7.

\section{$2 \quad$ Rate setting mechanism}

The rate escalation mechanism is one of the most important components of an incentive regulation (IR) plan. ${ }^{5}$ Such a mechanism can substitute for rate cases as a means to adjust utility rates for trends in input prices, demand, and other external business conditions that affect utility earnings. As such, it makes it possible to extend the period between rate cases and strengthen utility performance incentives. The mechanism can be designed so that the expected benefits of improved performance are shared equitably between utilities and their customers.

An approach to the design of price cap rate escalation mechanism has developed in North America that is grounded in theoretical and empirical research. This approach begins with consideration of the growth in the prices charged by an industry that earns, in the long run, a competitive rate of return. In such an industry, the long-run trend in revenue equals the long-run trend in cost. $^{6}$

\section{(1) trend $($ Revenue $)=$ trend $($ Cost $)$}

The assumption of a competitive rate of return is applicable to utility industries as much as to unregulated or competitively structured markets.

The revenue of any firm or industry is the sum of the trends in appropriately specified output price and quantity indexes.

(2) $\operatorname{trend}($ Revenue $)=\operatorname{trend}(P)+\operatorname{trend}(Y)$

Relations [1] and [2] together imply that the trend in an index of the prices charged by an industry earning a competitive rate of return equals the trend in its unit cost index.

\section{(3) $\operatorname{trend}(P)=\operatorname{trend}($ Cost $)-\operatorname{trend}(Y)=\operatorname{trend}(U C)$}

This result provides a conceptual framework for the design of price cap indexes (PCIs). Growth in a utility's rates can be measured by an actual price index. A PCI can limit the growth in this index. A stretch factor established in advance of plan operation can be added to the formula which slows PCI growth in a manner that shares with customers the expected benefits of improvements due to the stronger performance incentives of the IR plan. A PCI is calibrated to track the industry unit cost trend to the extent that

\section{(4) trend $(P C I)=$ trend $(U C)+$ Stretch Factor}

A properly calibrated PCI provides automatic rate adjustments for a wide array of external business conditions that affect the unit cost of utility operation. It can therefore

\footnotetext{
${ }^{5}$ For comprehensive discussion of incentive ratemaking see Baumol (1982), Shleifer (1985), Joskow and Schmalensee (1986), Laffont and Tirole (1993), and Lowry and Kaufmann (2002). Additional discussion can be found in Bell (2002), Jamasb and Pollitt (2003), Jamsab and Pollitt (2001), Lowry and Kaufmann (2006), and Fabrizio et al. (2007).

${ }^{6}$ See Bernstein and Sappington (1999) for details of the derivation of a price-cap index.
} 
generate compensatory rates and reduce utility operating risk without weakening performance incentives.

The design of PCIs that track the industry unit cost trend is aided by an additional result of index logic. The trend in an industry's total cost is the sum of the trends in appropriately specified industry input price and quantity indexes.

(5) $\operatorname{trend}($ Cost $)=\operatorname{trend}(W)+\operatorname{trend}(X)$

It follows that the trend in an industry's unit cost is the difference between the trends in industry input price and TFP indexes.

(6) $\operatorname{trend}(\mathrm{UC})=\operatorname{trend}(\mathrm{W})-\operatorname{trend}(\mathrm{TFP})$

Therefore, a PCI can be calibrated to track the industry unit cost trend if it is designed in accordance with the following formula ${ }^{8}$ :

(7) trend $(P C I)=$ trend $(W)-$ trend $(T F P)+$ Stretch Factor

The X factor term of the PCI would, in this case, be the sum of a TFP trend and a stretch factor.

Different treatments of input price and productivity growth are in most cases warranted when a PCI is calibrated to track the industry unit cost trend. The inflation measure should track short term input price growth while the $\mathrm{X}$ factor should generally reflect the long run trend of TFP. The recent long run trend in an industry's TFP is often, if not always, a good proxy for the prospective trend over the next several years while historical trends in input prices are sometimes poor predictors of the trends that will prevail in the near future.

\section{$3 \quad$ TFP targets}

In the North American approach to PCI design, the target or goal is typically to set the long run average growth trend in the TFP indexes using a sample of utilities. National or regional aggregates are commonly used for this purpose. ${ }^{9}$

This approach may be unreasonable when applied to a utility facing business conditions that differ markedly from those in the surrounding region. This problem

\footnotetext{
${ }^{7}$ Here is the full logic behind this result:

Using (3) and (5)

$$
\begin{aligned}
\operatorname{trend}(U C) & =\operatorname{trend}(\text { Cost })-\operatorname{trend}(Y) \\
& =(\operatorname{trend}(W)+\operatorname{trend}(X))-\operatorname{trend}(Y) \\
& =\operatorname{trend}(W)-(\operatorname{trend}(Y)-\operatorname{trend}(X)) \\
& =\operatorname{trend}(\mathrm{W})-\operatorname{trend}(T F P)
\end{aligned}
$$
}

${ }^{8}$ The CPI-X regulatory regime is a high-powered incentive scheme, which can provide strong incentive for efficient performance but can also expose the firms to considerable risk. For instance, if the X factor used is very challenging it might favour consumers at the risk of producers, and at times can create strong incentives on the part of firms to appeal the regulator's decision.

${ }^{9}$ The X factor in the current price cap index for Boston Gas, for instance, is based on the productivity trend of the gas distributors in the northeast United States. See Massachusetts Department of Public Utilities (formerly Department of Telecommunications \& Energy). 2003. Petition of Boston Gas Company d/b/a KeySpan Energy Delivery New England, pursuant to General Laws Chapter 164, § 94, and 220 C.M.R. § 5.00 et seq. for a General Increase in Gas Rates. D.T.E. 03-40. October 31, 2003. 
confronted the Ontario Energy Board as it attempted to develop rate adjustment mechanisms for the two large gas distributors in the province. Data were not readily available to compute the TFP trends of other Canadian gas utilities, such as Terasen Gas and Gaz Metropolitaine. Gas utilities in nearby areas of the United States, such as Michigan, northern Ohio, and upstate New York, have a considerably different operating environment that usually includes slow demand growth.

Under this circumstance, mathematical theory and econometric research can be used to generate TFP targets based on the classic treatment by Denny, Fuss, and Waverman (1981). This method has benefited from further development in Fuss (1994), Mullen (2001) and Kumbhakar and Lozano-Vivas (2005). Its starting point is the assumption that the actual cost incurred by a firm is the product of minimum total cost, $C^{*}$, and a term, $\eta$, that may be called the inefficiency factor.

$$
C=C^{*} \cdot \eta
$$

The inefficiency factor indicates how high the actual cost of a firm is above the minimum attainable level. Equation (9) indicates that the instantaneous growth rate of total cost is the sum of the growth rates of minimum total cost and the inefficiency factor.

(9) $\dot{C}=\dot{C}^{*}+\dot{\eta}$

For a well-behaved production technology, the minimum total cost of a firm is a function of various input prices $(W)$, output quantities $(Y)$, and variables that measure miscellaneous other business conditions $(Z)$. This function can be represented mathematically as

(10) $C^{*}=g(W, Y, Z) \cdot \eta$

The elasticity of cost with respect to each output variable $Y_{i}$ is denoted by $\varepsilon_{Y_{i}}$. The other elasticities and business condition variables are denoted analogously.

Total differentiation of Equation (10) with respect to time reveals that

$$
\dot{C}^{*}=\left(\sum_{i} \varepsilon_{Y_{i}} \cdot \dot{Y}_{i}+\sum_{h} \varepsilon_{Z_{h}} \cdot \dot{Z}_{h}+\sum_{j} \varepsilon_{W_{j}} \cdot \dot{W}_{j}\right)+\dot{g}
$$

The growth rate of total minimum cost can be seen to be the sum of two terms. The first is the sum of the products of the growth rates of the business condition variables and their corresponding cost elasticities. The second is the proportional shift in the cost function $(\dot{g})$.

Invoking Shephard's lemma, equation (11) may be rewritten as

$$
\dot{C}^{*}=\sum_{i} \varepsilon_{Y_{i}} \cdot \dot{Y}_{i}+\sum_{h} \varepsilon_{Z_{h}} \cdot \dot{Z}_{h}+\dot{W}^{*}+\dot{g}
$$

Here $\dot{W}^{*}$ is the growth rate of the optimal input price index. We assume for simplicity that this equals the growth of the actual input price index $(\dot{W})$.

Let us now define the growth rate of a TFP index (TFP) to be the difference between the growth rates of an elasticity-weighted output quantity index $\left(Y^{E}\right)$ and an input quantity index $(X) .{ }^{10}$ Formally

\footnotetext{
${ }^{10}$ In case we define the growth rate of TFP as the difference between a revenue-weighted output quantity index $\left(Y^{R}\right)$ and an input quantity index $(X)$, there will be an extra term in the final TFP decomposition term of (15) called the average use effect. It measures the difference between the growth rates of revenue and
} 
(13) $T \dot{F P}=\dot{Y}^{E}-\dot{X}$

The growth rate of the input quantity index is known to be the difference between the growth rates of cost and the input price index $(W){ }^{11}$

(14) $\dot{X}=\dot{C}-\dot{W}$

Equations (12) - (14) imply that ${ }^{12}$

(15) $T \dot{F F}=\left(1-\sum_{i} \varepsilon_{Y_{i}}\right) \dot{Y}^{E}-\sum_{h} \varepsilon_{Z_{h}} \cdot \dot{Z}_{h}-(\dot{g}+\dot{\eta})$

The growth rate of the TFP index has been decomposed theoretically into three terms. The first is the scale economy effect. Returns to scale are realized to the extent that incremental scale economies are available and output quantity grows. Incremental scale economies exist if the sum of the cost elasticities with respect to the output variables is less than 1.

The second term measures the effect on TFP growth of growth in the values of the $\mathrm{Z}$ variables. We will call this the other business conditions effect. If the cost elasticity of a

elasticity weighted output indexes. It effectively captures the difference between the effects of output growth on revenue and cost. It is non-zero to the extent that revenue and cost share weights differ and there are differences in the growth rates of output variables. In energy distribution industries, this term typically depends on trends in consumption per customer. There were such differences in Ontario, but the average use factor was accounted for in another part of the price cap design and, thus, we will only present the case where TFP is defined as the difference between an elasticity-weighted output quantity index $\left(Y^{E}\right)$ and an input quantity index. This provides an econometric decomposition of TFP whose results match those considered, and partly used, by the Ontario Energy Board.

${ }^{11}$ The input quantity index for each company is of Törnqvist form; see Törnqvist (1936) and Theil (1965) for seminal discussions of this index form. This means that its annual growth rate is determined by the general formula $\ln \left(X_{\mathrm{t}} / X_{\mathrm{t}-1}\right)=\sum_{j 1} 1 / 2 \cdot\left(S C_{j t}+S C_{j t-1}\right) \cdot \ln \left(X_{j t} / X_{j t-1}\right)$. For each company in each year $t, X_{j t}$ is the quantity of input category $j$, and $S C_{j t}$ is the cost share of input category $j$ in applicable total cost. The price index used in this study is similarly defined. Its general formula is $\ln \left(w_{t} / w_{t-1}\right)=\Sigma_{j 1} / 2 \cdot\left(S C_{j, t}+S C_{j, t-1}\right) \cdot \ln \left(w_{j t} / w_{j t-1}\right)$, where for each company in each year $t, w_{j t}$ is the price of input category $j$ and $S C_{j t}$ is as above. The elasticity weighed output quantity index is given by $\ln \left(Y_{t} / Y_{t-1}\right)=\Sigma_{i}\left(S E_{i}\right) \cdot \ln \left(Y_{i t} / Y_{i t-1}\right)$. Here for each company in each year $t, Y_{i t}$ is the amount of output $i$ and $S E_{i}$ is the share of output measure $i$ in the sum of estimated output elasticities.

12 The full derivation of this result is as follows:

$$
\begin{aligned}
& =\dot{Y}^{E}-(\dot{C}-\dot{W}) \\
& =\dot{Y}^{E}-\left[\left(\sum_{i} \varepsilon_{Y_{i}} \cdot \dot{Y}_{i}+\sum_{h} \varepsilon_{Z_{h}} \cdot \dot{Z}_{h}+\dot{W}+\dot{g}+\dot{\eta}\right)-\dot{W}\right] \\
& =\dot{Y}^{E}-\left[\left\{\sum_{i} \varepsilon_{Y_{i}}\left[\left(\sum_{i} \frac{\varepsilon_{Y_{i}}}{\sum_{i} \varepsilon_{Y_{i}}}\right) \cdot \dot{Y}_{i}\right]+\sum_{h} \varepsilon_{Z_{h}} \cdot \dot{Z}_{h}+(\dot{g}+\dot{\eta})\right\}\right] \\
& =\dot{Y}^{E}-\left[\sum_{i} \varepsilon_{Y_{i}} \dot{Y}^{E}+\sum_{h} \varepsilon_{Z_{h}} \cdot \dot{Z}_{h}+(\dot{g}+\dot{\eta})\right]
\end{aligned}
$$


given $\mathrm{Z}$ variable, $h$, is positive (negative), an increase in the value of the variable will decelerate (accelerate) TFP growth.

The third term measures the effect on TFP growth of the proportional shift in the cost function. It may be called the technological change effect. The cost function will shift downward (upward) if cost falls (rises) at given values of the business condition variables. A downward (upward) shift in the cost function will accelerate (decelerate) TFP growth.

The term $\dot{\eta}$ in the third bracket measures the effect on TFP growth of a change in inefficiency. We call this the inefficiency effect. A decline (increase) in inefficiency will accelerate (decelerate) TFP growth. Efficiency scores from a benchmarking exercise that can identify if utilities are superior, average or inferior cost performers can help in assigning stretch factors that can serve as a proxy for this term. For instance, utilities found to be inefficient have the potential for accelerated productivity growth and can have positive numbers added to their $\mathrm{X}$ factors that allow customers to share in the expected efficiency improvements over the plan term. ${ }^{13}$

The above results can be used to determine TFP targets. They require the estimation of cost elasticities using an econometric cost model, which are used to fit (15). In particular, TFP targets or values are computed using the econometric elasticity estimates and the changes in the values of business condition variables that correspond to the subject utility. This approach can be called econometric productivity projection. Before discussing how cost model estimates are used to obtain TFP targets, we turn to the data used to estimate these in the next section.

\section{$4 \quad$ Data}

\subsection{Data sources}

The primary source of the data used for US gas utilities is reports filed by them with state regulators. These reports often use as templates the Federal Energy Regulatory Commission (FERC) Form 2 report that interstate gas pipeline companies file. A uniform system of accounts has been established by the FERC to help utilities prepare this filing. Gas utility operating data from state reports are compiled by commercial venders such as Platts. We obtained our 2004 operating data from the Platts GasDat package.

Other sources of data were also employed. Detailed data on the delivery volumes and customers served by US gas utilities were obtained from Form EIA 176. ${ }^{14}$ Data on input prices were drawn from several sources. Whitman, Requardt \& Associates prepare Handy Whitman Indexes of trends in the construction costs of US gas utilities. Other sources of input price data include R.S. Means and Associates; the Bureau of Labor Statistics (BLS) of the US Department of Labor; and the Energy Information Administration (EIA) of the US Department of Energy.

\footnotetext{
${ }^{13}$ See Lowry et al. (2005) for the details of how a benchmarking exercise can help in this assignment. We note here that this term is not included in the TFP projections calculated since it appears as a separate term in the price cap plan.

${ }^{14}$ Good data on contract demands are unfortunately, not available from this or any other US source of which we are aware.
} 


\begin{tabular}{|c|c|c|c|c|c|}
\hline Region/Company & $\begin{array}{l}\text { No. of } \\
\text { Customers } \\
(2004)\end{array}$ & $\begin{array}{l}\text { Percen } \\
\text { t } \\
\text { Sample } \\
\text { Total } \\
\end{array}$ & Region/Company & $\begin{array}{l}\text { No. of } \\
\text { Customers } \\
(2004)\end{array}$ & $\begin{array}{l}\text { Percen } \\
\text { t } \\
\text { Sample } \\
\text { Total } \\
\end{array}$ \\
\hline Northeast & & & South Central & & \\
\hline Baltimore Gas \& Electric & 624,862 & & Alabama Gas & 460,921 & \\
\hline Central Hudson Gas \& Electric & 69,081 & & Louisville Gas and Electric & 316,311 & \\
\hline Connecticut Natural Gas & 151,127 & & Total & 777,232 & $2.5 \%$ \\
\hline Consolidated Edison of New York & $1,041,458$ & & EIA Regional Total & $10,240,944$ & \\
\hline Niagara Mohawk & 560,566 & & Southwest & & \\
\hline New Jersey Natural Gas & 453,983 & & Southwest Gas & $1,526,462$ & \\
\hline Nstar Gas & 252,576 & & Questar & 777,555 & \\
\hline Orange and Rockland Utilities & 123,577 & & Total & $2,304,017$ & $7.4 \%$ \\
\hline PECO Energy & 464,619 & & EIA Regional Total & $4,679,222$ & \\
\hline People's Natural Gas (PA) & 355,134 & & Northwest & & \\
\hline PG Energy & 159,242 & & Cascade Natural Gas & 217,336 & \\
\hline Public Service Electric \& Gas & $1,693,048$ & & Northwest Natural Gas & 586,461 & \\
\hline Rochester Gas and Electric & 293,334 & & Puget Sound Energy & 661,739 & \\
\hline Southern Connecticut Gas & 170,817 & & Total & $1,465,536$ & $4.7 \%$ \\
\hline Total & $6,413,424$ & $20.5 \%$ & EIA Regional Total & $2,282,62$ & \\
\hline EIA Regional Total & $14,210,646$ & & California & & \\
\hline Southeast & & & Pacific Gas \& Electric & $4,030,373$ & \\
\hline Atlanta Gas Light & $1,532,615$ & & San Diego Gas \& Electric & 805,772 & \\
\hline Public Service of North Carolina & 390,824 & & Southern California Gas & $5,266,356$ & \\
\hline Washington Gas Light & 980,686 & & Total & $10,102,501$ & $32.4 \%$ \\
\hline Total & $2,904,125$ & $9.3 \%$ & EIA Regional Total & $10,432,623$ & \\
\hline EIA Regional Total & $6,554,338$ & & Total For Sample & $31,220,255$ & \\
\hline Midwest and Plains & & & Industry Total * & $68,748,753$ & \\
\hline Consumers Energy & $1,690,874$ & & & & \\
\hline East Ohio Gas & $1,217,546$ & & Percentage of US Total & $45.4 \%$ & \\
\hline Illinois Power & 414,015 & & & & \\
\hline Madison Gas and Electric & 131,674 & & Number of Sampled Firms & 36 & \\
\hline North Shore Gas & 153,856 & & & & \\
\hline NICOR Gas & $2,092,607$ & & Average for Sample Cos. & 867,229 & \\
\hline Peoples Gas Light \& Coke & 812,705 & & & & \\
\hline Wisconsin Gas & 570,927 & & & & \\
\hline Wisconsin Power \& Light & 169,216 & & & & \\
\hline Total & $7,253,420$ & $23.2 \%$ & & & \\
\hline EIA Regional Total & $20,348,354$ & & & & \\
\hline
\end{tabular}

\section{Table 1: Sampled US gas utilities for empirical research}

* Source for US Total: US Energy Information Administration, Natural Gas Annual 2004 
Our sample has data for 36 gas distributors and includes most of the nation's larger utilities. ${ }^{15}$ The sampled utilities are listed by region in Table 1 . They served about $45 \%$ of gas customers in the continental US. The sampled utilities all provide distributor services but vary in their involvement in gas storage and transmission. A few companies, such as East Ohio Gas, Pacific Gas \& Electric, and Southern California Gas, are, like Union, extensively involved in both activities. Others, like NICOR Gas that operates extensive Illinois storage facilities, are greatly involved in one of the two activities. Many of the companies are not significantly involved in either activity.

Most of the data that we gathered on the operations of Enbridge and Union were filed by the companies in regulatory proceedings. The other source of significant amount of data was Statistics (Stats) Canada, primarily used to obtain input price data.

It is interesting to compare the number of customers served by the sampled US utilities to those of Enbridge and Union. In 2004, the Ontario companies served more than 1.6 million and 1.2 million customers, respectively. Union operates a sizable gas transmission and storage system in addition to its distribution operations. Thus, both operate at scales that are well above the norm for our sample. However, the sample includes several companies with similar or larger operating scales. Summary statistics of model variables provided in Table 2 illustrate these comparisons.

\begin{tabular}{|l|l|l|l|r|r|}
\hline Variable & Units & $\begin{array}{l}\text { U.S. } \\
\text { Sample } \\
\text { Average }\end{array}$ & $\begin{array}{l}\text { U.S. } \\
\text { Sample } \\
\text { Maximum }\end{array}$ & $\begin{array}{l}\text { U.S. } \\
\text { Sample } \\
\text { Minimum }\end{array}$ & $\begin{array}{l}\text { Ontario } \\
\text { Sample } \\
\text { Average }\end{array}$ \\
\hline Time Period & Years & $\mathbf{1 9 9 4 - 2 0 0 4}$ & $\mathbf{1 9 9 4 - 2 0 0 4}$ & $\mathbf{1 9 9 4 - 2 0 0 4}$ & \multicolumn{2}{|c|}{$\mathbf{2 0 0 0 - 2 0 0 6}$} \\
\hline Total Gas Delivery Cost & 1000 Dollars & 314,896 & $1,701,468$ & 32,622 & N/A \\
\hline Number of Customers & Count & 804,016 & $5,266,356$ & 59,747 & $1,409,351$ \\
\hline Retail Deliveries & MDt & 179,113 & $1,170,744$ & 15,662 & 845,853 \\
\hline Line Miles & Miles & 10,223 & 46,095 & 936 & 20,247 \\
\hline Price of Capital Services & Index Number & 11.67 & 20.63 & 6.25 & 15.95 \\
\hline Price of Labor Services & Index Number & 148.64 & 185.78 & 122.11 & 175.41 \\
\hline Price of Materials & Index Number & 98.83 & 109.1 & 90.27 & 106.06 \\
\hline Percent of Line Miles Not Cast Iron & Percent & 0.91 & 1.00 & 0.47 & 0.98 \\
\hline Number of Power Customers Served & Count & 572,397 & $4,985,193$ & 0.00 & 0.00 \\
\hline
\end{tabular}

Table 2: Summary statistics of variables in the benchmarking study: Gas delivery

\subsection{Defining Cost}

For all sampled utilities in our study, the applicable total cost was calculated as applicable operations and maintenance (O\&M) expenses plus the cost of gas plant ownership. Applicable O\&M expenses were defined as the total net or non-capitalized O\&M expenses of the utility less any expenses for natural gas production or procurement, transmission services provided by others, or franchise fees. The operations corresponding to this definition of cost include distribution (local delivery), account, information, and other customer services, and any storage and transmission services that a utility may provide.

The input price and quantity indexes both featured three input categories: capital, labor, and materials and services (M\&S). The cost of labor was defined as the salaries and wages

\footnotetext{
${ }^{15}$ Large distributors that are not represented in the sample include Atmos (owner of the former Lone Star Gas System), Columbia Gas of Ohio, Entex, Laclede Gas, Michigan Consolidated Gas, Minnegasco, and National Fuel Gas.
} 
that contributed to net O\&M expenses plus all expenses for pensions and other benefits. Net rather than gross labor cost data are preferable to avoid double counting labor expenses that utilities capitalize. In calculating the cost share for labor we also included expenses for pensions and other benefits. The pension and other benefit expenses attributable to net O\&M were provided by Union and were, for the most part, estimated for Enbridge. Lacking a good basis for analogous estimates for US utilities we used their reported pension and benefit expenses without adjustment.

The cost of natural gas used in system operation was itemized only by Union, which operates numerous compressors on its transmission and storage system. Since the cost of this gas will be recovered by a separate mechanism during the regulatory period, we exclude this cost from the calculations in our research.

The cost of M\&S inputs was defined to be applicable O\&M expenses net of expenses for labor, and in the case of Union natural gas. This residual input category includes the services of contract workers, insurance, real estate rents, equipment leases, materials, and miscellaneous other goods and services. The M\&S expenses of Enbridge and Union were reduced further by the reported demand-side management expenses of the companies.

For the US companies, National Compensation Survey (NCS) data for 2004 were used to construct average wage rates that correspond to each distributor's service territory. Values for other years were calculated by adjusting the 2004 level for changes in employment cost trends. For this purpose, we used the employment cost index (ECI) for electric, gas, and sanitary workers. Regional labor price trends were obtained by adjusting the trends in this national ECI for the difference in the trends of comprehensive regional and national ECIs. All of these ECIs are calculated by the U.S. Bureau of Labor Statistics. For the non-labor O\&M price index we used the comprehensive chain-weighted gross domestic product price index. We have found that this index tracks the trend in utility materials and services rather well. For the Ontario utilities we used a Stats Canada index of Ontario construction worker total compensation as the price sub-index for labor was. The price sub-index for other O\&M inputs was the Ontario gross domestic product price index (GDPIPI) for all goods and services.

The study uses a service price and quantity approach to measuring the cost of plant ownership that is based on the economic value of utility plant. ${ }^{16}$ Under this approach, the cost of capital is the product of capital price and quantity indexes. This method controls for differences between utilities in the age of their investments. In particular, the cost of capital was valued using two approaches: geometric decay (GD) and an alternative approach to capital costing that is designed to reflect how capital cost is calculated under cost of service (COS) regulation. ${ }^{17}$ We report here only the results for the COS approach since that was used in the approved $\mathrm{X}$ factor for Union. The salient features of the COS approach to capital costing are a book or historic dollar valuation of plant, and straight-line depreciation.

Both capital costing methods require the decomposition of cost into a price and a quantity index in order to calculate industry input price and productivity trends. The capital price is sometimes called a rental or service price since it reflects the cost of owning a unit of capital much like prices for rental services do in competitive markets.

\footnotetext{
${ }^{16}$ See the seminal work of Hall and Jorgensen (1967).

17 The GD approach uses the replacement cost of capital concept and the geometric decay of capital to account for depreciation, while the COS approach computes the value of capital based on its book value.
} 
The capital quantity index is, effectively, an index of the real or inflation-adjusted value of plant where indexes of utility construction costs are used as deflators.

The capital service price index is calculated as construction cost indexes times the rate of return, reflecting the opportunity cost of capital, and construction cost indexes times depreciation rates, reflecting the cost of depreciation. The construction cost index $\left(W K A_{t}\right)$ used in the U.S. calculations was the regional Handy-Whitman index of gas utility construction costs for the relevant region. ${ }^{18}$ The capital price sub-index for the Ontario utilities was constructed from data on construction cost trends and the rate of return. The construction cost index used in the Ontario calculations was, as noted above, a deflator for Canada's gas distribution capital stock prepared by Stats Canada. ${ }^{19}$ The rate of return was an average of Stats Canada indexes for long term corporate bond yields and the return on equity of Canada utilities.

\section{$5 \quad$ Cost model details}

\subsection{Cost model}

Economic theory can be used to guide cost model development. ${ }^{20}$ As already stated, the minimum total cost of a firm is a function of its output and the prices it pays for capital, labor, and other production inputs. A firm's output can be multidimensional and may require several variables for effective measurement.

\footnotetext{
${ }^{18}$ These data are reported in the Handy-Whitman Index of Public Utility Construction Costs, a publication of Whitman, Requardt and Associates.

${ }^{19}$ No analogous index of the cost of constructing Canadian gas distribution systems is, apparently, available.

${ }^{20}$ Unlike the case for power distribution, the number of studies that examine the cost structure of gas distribution utilities are limited. Among these are a study by Farsi et al. (2007) that examine the cost of Switzerland's gas distribution industry using panel data on 26 Swiss utilities. In the study, the authors specify a model where deliveries are designated as the only output but the effect of customers on cost is captured by a customer density variable measured as customer numbers per network length. Other network characteristic variables, also know as environmental or z-variables, such as the size of service territory, load factor and the number of terminal blocks are also included in the model. They do not find much economies of scale but conclude that there is room for cost efficiency improvement. They also find significant economies of density and conclude that for a given service territory and customer numbers, producers can reduce their cost by increasing deliveries. Fabbri et al. (2000) who study the cost of gas distribution utilities in Italy find the number of customers to be more important in explaining gas distribution cost than deliveries. Our work indicates the same finding. They also identify considerable economies of density but very little economies of scale. A study by Kim and Lee (1995) identifies total deliveries as output, and customer density, average consumption and the number of actual to potential customers as important cost drivers of gas distributors of Korea. Their study, like the ones above, indicates that scale economies have been exhausted by the almost all the distributors. To compare the efficiency of municipal and private gas distributors, Hollas and Stansell (1994) use data of 49 municipal and 63 investor-owned utilities and provide one of the few gas distribution studies using US data. They estimate economic efficiency of these firms, however, using a behavioral profit function and do not examine the cost structure of the firms in the industry. Therefore, our study provides a unique contribution to the literature by estimating a cost function model of the US gas distribution industry using the latest data that is available.
} 
We adopt the translog functional form for the cost model. ${ }^{21}$ This very flexible function is common in econometric cost research and is among the most reliable of several available flexible forms. ${ }^{22}$ The general form of the function we use can be written as:

$$
\begin{aligned}
& \ln C=\alpha_{o}+\sum_{i} \alpha_{i} \ln Y_{i}+\sum_{j} \alpha_{j} \ln W_{j}+\frac{1}{2}\left[\sum_{i} \gamma_{i} \ln Y_{i} \ln Y_{i}+\sum_{j} \sum_{n} \gamma_{j n} \ln W_{j} \ln W_{n}\right] \\
& +\sum_{i} \sum_{j} \gamma_{i j} \ln Y_{i} \ln W_{j}+\sum_{\ell} \alpha_{\ell} \ln Z_{\ell}+\alpha_{T} T+\sum_{j} \alpha_{j T} \ln W_{j} T+\varepsilon .
\end{aligned}
$$

Here, $Y_{i}$ denotes one of several variables that quantify output and $W_{j}$ denotes one of several input prices. The $Z$ 's denote the additional business conditions, $T$ is a trend variable, and $\varepsilon$ denotes the error term. ${ }^{23}$ In addition, $C$ denotes total cost. ${ }^{24}$

Our translog model includes all second order terms except output interaction terms. The inclusion of such interaction terms leads to a violation of output regularity, for nearly two-thirds of the observations, which is needed for positive marginal costs. This is a theoretical violation, but it also presents practical difficulties since we use firm specific output elasticities in TFP target calculation. Likely reasons for this violation include multicollinearity between the output variables and a sample of inadequate size. We believe that the translog model without output interaction terms preserves as much flexibility as possible in the cost model while still permitting the multidimensional output specifications that are needed in gas utility cost research. Our model also includes input price and trend interaction terms, which allows us to identify non-neutral technical change. We do not include output and trend interaction terms to further preserve degrees of freedom.

Cost theory requires a well-behaved cost function to be linearly homogeneous in input prices. This implies the following three sets of restrictions on the parameter values.

\footnotetext{
${ }^{21}$ The transcendental logarithmic (or translog) cost function can be derived mathematically as a second order Taylor series expansion of the logarithmic value of an arbitrary cost function around a vector of input prices and output quantities.

${ }^{22}$ See Guilkey et al. (1983) and Gagne and Ouellette (1998).

${ }^{23} \mathrm{~A}$ variety of methods are available to specify and estimate cost functions. In addition to what we present in this paper, which treats the inefficiency term having symmetric distribution, another group of methods are available that treat the inefficiency term as being one-sided. The most important parametric approach of this sort is stochastic frontier analysis (SFA). Like our model, an SFA cost model allows for the inclusion of business conditions that affect cost and also includes a two component error term, one of which has a onesided distribution. This term reflects inefficiency while the other term reflects random error. Thus, SFA provides a way to disentangle random shock and inefficiency. The parameters of the distribution of the inefficiency term and those of the cost model are estimated by maximum likelihood. There are a number of studies that employ this approach to estimate inefficiency in gas distribution. The study of the Swiss gas distribution industry by Farsi et al. (2007) is one such example.

${ }^{24}$ We estimate a total cost function for the gas distribution industry of the US in our study as do a few of the studies we discussed earlier. Fabbri et al. estimate a total cost function because Italian gas distributors face price control rather than rate of return regulation. Therefore, they find the assumption of cost minimization with respect to all inputs appropriate. Farsi et al. also estimate a total cost function. In a study used to identify optimal size and vertical integration in Argentine and UK gas distribution industries, however, Casarin (2007) discusses the need to estimate short-run cost functions for this industry. He argues that a restricted equilibrium is likely to hold where quasi-fixed factors do not instantaneously adjust to their longrun equilibrium and that firms operate off their expansion paths. We use the long-run cost function in our study because our primary interest is to infer total productivity targets, which require this. In addition, the assumption of cost minimization is not required for cost function estimation, in that a cost model can be specified as the sum of random minimum cost and an inefficiency-factor that capture the deviation of observed cost from minimum due to errors to optimize.
} 
(17) $\sum_{j=1}^{N} \frac{\partial \ln C}{\partial \ln W_{j}}=1$

(18) $\sum_{j=1}^{N} \frac{\partial^{2} \ln C}{\partial \ln W_{j} \partial \ln W_{n}}=0 \quad \forall n=1 \ldots N$,

(19) $\sum_{j=1}^{N} \frac{\partial^{2} \ln C}{\partial \ln W_{j} \partial \ln Y_{h}}=0 \quad \forall h=1 \ldots M$

These conditions were imposed prior to model estimation. In addition, conditions that ensure symmetric second cross-partial derivatives are also imposed prior to estimation.

Estimation of the parameters of equation (16) is now possible but this approach does not utilize all of the information available in helping to explain the factors that determine cost. Better parameter estimates can be obtained by augmenting the cost equation with some of the cost share equations implied by Shephard's Lemma. The general form of a cost share equation for a representative input price category, $j$, can be written as:

(20) $S C_{j}=\alpha_{j}+\sum_{i} \gamma_{i j} \ln Y_{i}+\sum_{n} \gamma_{j n} \ln W_{n}$

The parameters in this equation also appear in the total cost function. Thus, information about cost shares can be used to obtain more efficient estimates of the cost model parameters.

We estimated the parameters of the cost model using data for 36 US gas distributors for the 1994-2004 sample period. We discuss the variables used in the model in the next section.

\subsection{Estimation method and results}

To estimate model parameters, we employed a variant of an estimation procedure first proposed by Zellner (1962). ${ }^{25}$ If there exists a contemporaneous correlation between the error terms in a system of regression equations, more efficient estimates of their parameters can be obtained using a Feasible Generalized Least Squares (FGLS) approach, which we iterate to convergence. ${ }^{26}$ We estimate the unknown disturbance matrices consistently. Thus, our estimates are equivalent to Maximum Likelihood Estimates (MLE) and possess all the highly desirable properties of MLEs. ${ }^{27}$

Since the cost share equations by definition must sum to one at every observation, one cost share equation is redundant and must be dropped. ${ }^{28}$ This does not pose a problem since the MLE procedure is invariant to any such reparameterization. Hence, the choice of which equation to drop will not affect the resulting estimates.

Explanatory variables of the model are mean-scaled and logged prior to estimation. This is a common procedure in translog cost system estimation and allows us to interpret first order terms of the model as elasticities at the mean or for an 'average firm.'

\footnotetext{
${ }^{25}$ See Zellner, A. (1962)

${ }^{26}$ That is, given any two estimated consecutive disturbance matrices, if we form another matrix that is their difference, its determinant is approximately zero in the final run.

27 See Dhrymes (1971), Oberhofer and Kmenta (1974), Magnus (1978).

${ }^{28}$ This equation can be estimated indirectly from the estimates of the parameters remaining in the model.
} 
There are three output quantity variables in our model: the number of retail customers, the volume of total retail deliveries, and the sum of transmission and distribution line miles. ${ }^{29}$ We also include input price variables for capital, labor, and other O\&M inputs in our model. We expect the first order estimates of all these variables to have positive signs.

Two additional business condition variables are included in the cost model. One is the percentage of distribution main not made of cast iron. This is calculated from American Gas Association data. Cast iron pipes were common in gas system construction in the early days of the industry. They are more heavily used in the older distribution systems found in the north eastern states. Greater use of cast iron typically involves high O\&M expenses, and may also involve an expensive program of replacement investment. The higher the value of this variable, the fewer the cast iron mains that a company owns. Hence, we expect the sign for this variable's parameter to be negative.

A second additional business condition variable in the model is the number of power distribution customers served by the utility. This variable is intended to capture the extent to which the company has diversified into power distribution. Generally, the greater the number of power customers the lower the cost due to the realization of economies from such diversification. We therefore expect the value of this variable's parameter to be negative. ${ }^{30}$

The cost model also contains a trend variable. This permits predicted cost to shift over time for reasons other than changes in the specified business conditions. A trend variable captures the net effect on cost of diverse conditions, which include technological change in the industry. We note that our cost model satisfies the usual regularity conditions needed for theoretical conformity. Monotonicity of the estimated cost function is met since all the predicted share equations are positive at all data points. For concavity, we compute a matrix of second order partial derivatives of the cost function with respect to input prices to check whether it is negative semi-definite, and also compute the bordered Hessian to check whether it is negative definite. We find both conditions are met at all data observations. Estimation results for the model are reported in Table 3.

\footnotetext{
${ }^{29}$ We have specified three of the most important output drivers of gas distribution cost in our model; they are among the ones used in the other studies mentioned earlier. Gas distribution companies must configure their systems to accommodate the maximum amount of gas demanded by end-users. Thus, peak demand is one important dimension of their output. As in power distribution, peak demand data for gas distribution is not publically available, and it can not be easily verified in the limited number of cases where it may be privately available. To an extent, the amount of gas volume carried or delivered serves a proxy for peak demand. Since gas distribution companies must also build their systems to accommodate each additional connection, the number of customers or connections is another important dimension of the output that they provide. We find that customer numbers to be the most significant output cost drivers in gas distribution in our study. A number of gas cost studies treat line length as an output or output characteristic variable. An example is Bernard et al. (2002). Others use line miles to construct a customer density variable, which is accounted for by the inclusion of both lines miles and customer numbers in our model.

${ }^{30}$ We tried a number of additional business condition variables such as frost depth, percent deliveries to residential and commercial customers, load factor and earthquake dummy variables, which were all statistically insignificant. We also experimented with several control variables for storage and transmission activity without any success. Since the model is not used to assess cost levels, the lack of controls for such work is not relevant.
} 


\begin{tabular}{|l|r|r|l|r|r|}
\hline $\begin{array}{l}\text { Explanatory } \\
\text { variable }\end{array}$ & $\begin{array}{l}\text { Estimated } \\
\text { Coefficient }\end{array}$ & \multicolumn{1}{|c|}{ t-statistic } & Explanatory variable & $\begin{array}{l}\text { Estimated } \\
\text { Coefficient }\end{array}$ & t-statistic \\
\hline L & 0.215 & 13.96 & N & 0.606 & 13.71 \\
\hline LL & -0.691 & -4.96 & NN & 0.087 & 1.50 \\
\hline LK & -0.122 & -8.36 & V & 0.082 & 2.00 \\
\hline LN & -0.056 & -4.09 & VV & -0.039 & -0.97 \\
\hline LV & 0.050 & 4.23 & M & 0.201 & 6.70 \\
\hline LM & 0.007 & 0.77 & MM & -0.066 & -1.29 \\
\hline LTrend & 0.008 & 2.69 & NIM & -1.001 & -13.11 \\
\hline K & 0.523 & 83.33 & NE & -0.007 & -7.07 \\
\hline KK & 0.171 & 10.84 & Trend & -0.012 & -6.09 \\
\hline KN & -0.054 & -4.65 & Constant & 8.133 & 527.17 \\
\hline KV & 0.019 & 1.78 & System Rbar-Squared & 0.979 & \\
\hline KM & 0.038 & 3.68 & Sample Period & $1994-2004$ & \\
\hline KTrend & 0.006 & 6.74 & Number of Observations & 396 & \\
\hline
\end{tabular}

Table 3: Econometric model of gas utility base rate

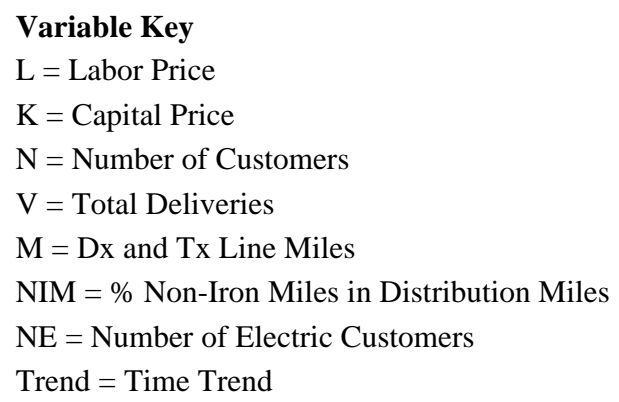

All of the key cost function parameter estimates are statistically significant. Moreover, all are plausible as to sign and magnitude. With regard to the first order terms, cost is higher the higher are the input prices and the output quantities. At sample mean values of the business condition variables, a $1 \%$ increase in the number of customers raises cost by $0.61 \%$. A $1 \%$ hike in total throughput raises cost by about $0.08 \%$. A $1 \%$ hike in the line miles raises cost by about $0.20 \%$. The number of customers served is clearly the dominant output-related cost driver. The sum of the elasticities of the output variables is 0.89 . This means that simultaneous $1 \%$ growth in all three output dimensions raises total cost by only $0.89 \%$ for a firm with a sample mean operating scale.

The results suggest, importantly, that the scale economies available from incremental output growth do not diminish materially with operating scale. This is due to the fact that the parameters of the quadratic terms for the output variables are not sizable and/or positively-signed. The quadratic terms for delivery volumes and line miles are, in fact, negatively signed. Since Enbridge and Union are both large companies facing brisk output growth, they both have good opportunities to realize scale economies and this should materially bolster their productivity growth.

Turning to results for the input prices, the elasticity of cost with respect to the price of capital services is about $0.52 \%$. This is more than double the estimated elasticity of the price of labor. This comparison reflects the capital intensiveness of the gas distribution business. 
The table also reports the system $\mathrm{R}^{2}$ statistic for the model. This measures the ability of the model to explain variation in the sampled costs of distributors. Its value is 0.979 , suggesting that the explanatory power of the model is high. We note, however, that high $\mathrm{R}^{2}$ values are often encountered in cost models estimated using a sample of companies with diverse operating scales.

\section{$6 \quad$ Econometric projection of TFP}

Using results from the econometric cost model, and values of the business conditions for Union and Enbridge, we obtain econometric TFP targets for each company. In this exercise, we calculate each company's rate of technological change to be the value of the trend variable parameter and the trend of each company's input prices times the respective coefficient estimates of trend-input price interaction terms. We then add this to each company's estimated scale economy effect resulting from the growth in their output during the sample period. This depends on the availability of incremental scale economies from growth in output and on the trend in output growth.

\begin{tabular}{|c|c|c|}
\hline & \multicolumn{2}{|c|}{ COS Capital Costing } \\
\hline & Enbridge & Union \\
\hline Sample Years & 2000-2006 & 2000-2006 \\
\hline \multicolumn{3}{|l|}{ Output Elasticity Estimates } \\
\hline Customers [A] & 0.648 & 0.622 \\
\hline Total Deliveries [B] & 0.057 & 0.014 \\
\hline Line Miles [C] & 0.169 & 0.163 \\
\hline Sum of Output Elasticities [D=A+B+C] & 0.874 & 0.799 \\
\hline \multicolumn{3}{|l|}{ Output Index Weights } \\
\hline Customers $[\mathrm{E}=\mathrm{A} /(\mathrm{A}+\mathrm{B}+\mathrm{C})]$ & $74.14 \%$ & $77.85 \%$ \\
\hline Total Deliveries $[\mathrm{F}=\mathrm{B} /(\mathrm{A}+\mathrm{B}+\mathrm{C})]$ & $6.52 \%$ & $1.75 \%$ \\
\hline Line Miles $[\mathrm{G}=\mathrm{C} /(\mathrm{A}+\mathrm{B}+\mathrm{C})]$ & $19.34 \%$ & $20.40 \%$ \\
\hline \multicolumn{3}{|l|}{ Output Subindex Growth } \\
\hline Customer $[\mathrm{H}]$ & $3.25 \%$ & $2.02 \%$ \\
\hline Total Delivery [I] & $0.42 \%$ & $-0.51 \%$ \\
\hline Line Miles [J] & $2.77 \%$ & $1.29 \%$ \\
\hline Elasticity Weighted Output Growth $\left[\mathrm{K}=\mathrm{E}^{*} \mathrm{H}+\mathrm{F}^{*} \mathrm{I}+\mathrm{G}^{*} \mathrm{~J}\right]$ & $2.97 \%$ & $1.82 \%$ \\
\hline \multicolumn{3}{|l|}{ Input Price Subindex Growth } \\
\hline Growth in Labor Price [L] & $3.78 \%$ & $3.74 \%$ \\
\hline Growth in Capital Price [M] & $0.50 \%$ & $-1.11 \%$ \\
\hline \multicolumn{3}{|l|}{ Input Price*Trend Parameters } \\
\hline Trend*Labor Price [R] & 0.008 & 0.008 \\
\hline Trend*Capital Price [S] & 0.006 & 0.006 \\
\hline Trend Parameter Estimate [T] & -0.0117 & -0.0117 \\
\hline Returns to Scale [U=(1-D)*K] & $0.37 \%$ & $0.37 \%$ \\
\hline Technological Change $[\mathrm{V}=-(\mathrm{T}+\mathrm{L} * \mathrm{R}+\mathrm{N} * \mathrm{~S})]$ & $1.13 \%$ & $1.14 \%$ \\
\hline TFP Projection [U+V] & $1.51 \%$ & $1.51 \%$ \\
\hline
\end{tabular}

Table 4: TFP growth projections from econometric research: No other business condition effects included 
Following mathematical theory, we measure the opportunity for incremental scale economies of each company as 1 minus the sum of its estimated output elasticities. We measure output growth as the average annual growth in each company's elasticityweighted output index from 2000 to 2006 . The expected scale effects are the product of these two terms. Results of this analysis are reported in Table 4. The TFP trend targets for both Enbridge and Union are 1.51\%.

The econometric approach to TFP target setting reflects the adjustment of cost to changing business conditions in the long run. In this case, it provides us with an estimate of the effect of cast iron replacement on TFP growth. ${ }^{31}$ This could potentially be added to the econometric TFP trend target for Enbridge since it has been reducing the amount of cast iron on its system in recent years and expects to accelerate the replacement during the IR plan term. As discussed above, we find that cast iron mains raise total cost. This finding implies that a reduction in cast iron accelerates TFP growth in the long run. However, the short and medium term effect on TFP growth may be different since the O\&M cost savings may be offset initially by the cost impact of the installation of new pipe. As an extra check, we therefore regressed the growth in the TFP of our sampled US utilities on the change in their cast iron reliance using data for the sample period. The estimated effect of reduced cast iron reliance on cost was found to be statistically insignificant.

Nevertheless, we include the effects of the other business conditions in the econometric projection of TFP to illustrate their impact. Table 5 presents these results. The values for technological change and scale economy effects are calculated the same way as in Table 4, thus, we do not replicate the details of their calculation in this table. We simply present the values for these two parts and subtract the effect of the other business conditions, whose calculation is presented in this table, from their sum. We note that the implied TFP projection rises from $1.51 \%$ to $1.87 \%$.

\begin{tabular}{|c|c|c|}
\hline & \multicolumn{2}{|c|}{ COS Capital Costing } \\
\hline & Enbridge & Union \\
\hline Sample Years & 2000-2006 & 2000-2006 \\
\hline Returns to Scale $[\mathrm{A}]^{1}$ & $0.37 \%$ & $0.37 \%$ \\
\hline 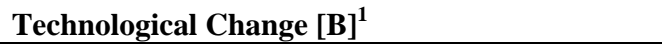 & $1.13 \%$ & $1.14 \%$ \\
\hline \multicolumn{3}{|l|}{ Growth in Other Business Condition Variables } \\
\hline Growth in \% Non-Cast Iron steel [C] & $0.36 \%$ & $0.36 \%$ \\
\hline Growth in Electric Customers [D] & $0.00 \%$ & $0.00 \%$ \\
\hline \multicolumn{3}{|l|}{ Parameters of Other Business Condition Variables } \\
\hline$\%$ Non-Cast Iron steel [E] & -1.001 & -1.001 \\
\hline Electric Customers [F] & -0.007 & -0.007 \\
\hline Other Business Conditions Effect [G=C*E+E*F] & $-0.36 \%$ & $-0.36 \%$ \\
\hline TFP Projection [A+B-G] & $1.87 \%$ & $1.87 \%$ \\
\hline
\end{tabular}

\section{Table 5: TFP growth projections from econometric research: Other business condition effects included}

1: The details for these elements of the TFP projection are the same as in the previous table.

\footnotetext{
${ }^{31}$ The other business condition variable is the number of electric customers. Since neither utility has electric customers, this business condition variable does not figure into the econometric TFP projection.
} 
As indicated earlier, the replacement of cast iron pipes accelerates expected productivity growth. Therefore, rate increases should be slower to account for this expected growth, awarding some of the benefits from this to customers. As we noted above, however, we can only expect the benefits of such replacements to have an in effect in the long term since such replacements will be accompanied by an increase in capital and labor inputs in the short-run that can constrain the growth in productivity.

\section{Concluding remarks}

We have presented a practical method for calculating the TFP targets for utility rate adjustment mechanisms. The method relies on econometric cost research and mathematical theory of TFP growth drivers. In both the utilities' cases, the TFP targets produced by the econometric projection are $1.51 \%$, and are somewhat higher if we account for the other business conditions effect.

The productivity based North American price cap plan requires the externalization of TFP used in setting rates. In the absence of 'peer' data, the method outlined in this paper provides a way to accomplish this. For instance, we computed the TFP index growth rate for Enbridge over this period, using its own data, and found the value to be $0.6 \%$. Thus, the difference between Enbridge's TFP performance based on its own data and external information highlights the importance of methods that permit the externalization of TFP calculations even in the absence of 'peer' industry data. The method we have outlined in this paper is important in this regard and has formed the basis for the price cap index of a large Ontario gas utility for the current regulatory period of 2008-2012. In addition, the method has another feature that makes it useful under a variety of operating conditions. If any major structural change is expected that would significantly alter expected future TFP growth from past trends, the method allows us to use projected values of driver variables to quantify the TFP growth departure from the past.

\section{$8 \quad$ References}

American Gas Association (various issues) Gas Facts. Arlington, VA.

Bauer P. (1990) "Decomposing TFP Growth in the Presence of Cost Inefficiency, Nonconstant Returns to Scale, and Technological Progress," The Journal of Productivity Analysis, 1; 287-299.

Baumol W.J. (1982) "Productivity Incentive Clauses and Rate Adjustment for Inflation,” Public Utilities Fortnightly, 11-18.

Bell, M. (2002) "Performance-Based Regulation: A View from the Other Side of the Pond,” The Electricity Journal, January/February: 67-73.

Bernard, J.-T., D. Bolduc and A. Hardy (2002) “The Costs of Natural Gas Distribution Pipelines: The Case of SCGM, Quebec,” Energy Economics, 24 (5): 425-38. 
Breusch, T. and A.R. Pagan (1980) "The LaGrange Multiplier Test and its Applications to Model Specification in Econometrics,” Review of Economic Studies, 47: 239-54.

Bureau of Economic Analysis (various issues) Unpublished Data on the Stocks and Service Lives of the Capital of Local Distribution Companies, US Department of Commerce: Washington, D.C.

Bureau of Economic Analysis (various issues) Survey of Current Business, US Department of Commerce: Washington, D.C.

Bureau of Labor Statistics (1998) National Compensation Survey, US Department of Labor: Washington, D.C.

Buse, A. (1982) "The Likelihood Ratio, Wald and LaGrange Multiplier Tests: An Expository Note,” The American Statistician, 62: 153-7.

Casarin, A. A. (2007) "Efficient Industry Configurations in Downstream Gas Markets: An Empirical Assessment,” Energy Economics, 29 (2): 312-28.

Denny, M., M. Fuss and L. Waverman (1981) “The Measurement and Interpretation of Total Factor Productivity in Regulated Industries, with an Application to Canadian Telecommunications," in: Cowing T.G. and R.E. Stevenson (eds.), Productivity Measurement in Regulated Industries. Academic Press: New York.

Dhrymes, P. J. (1971) "Equivalence of Iterative Aitkin and Maximum Likelihood Estimators for a System of Regression Equations,” Australian Economic Papers, 10: 2024.

Diewert, W.E. (1981) "The Theory of Total Factor Productivity Measurement in Regulated Industries,” in: Cowing T.G. and R.E. Stevenson (eds.), Productivity Measurement in Regulated Industries. Academic Press: New York.

Fabbri, P., F. Giovanni and R. Giandrone. (2000) "Costs, Technology and Ownership of Gas Distribution in Italy,” Managerial and Decision Economics, 21 (2): 71-81.

Fabrizio, K., N. Rose, C. and Wolfram (2007) "Do Markets Reduce Costs? Assessing the Impact of Regulatory Restructuring on US Electric Generation Efficiency," American Economic Review, 97 (4): 1250-1277.

Farsi, M. and M. Filippini (2004) "Regulation and Measuring Cost-Efficiency with Panel Data Models: Application to Electricity Distribution Utilities," Review of Industrial Organization, 25: 1-19.

Farsi, M., M. Filippini and M. Kuenzle (2007) "Cost Efficiency in the Swiss Gas Distribution Sector,” Energy Economics, 29: 64-78.

Federal Energy Regulatory Commission (various issues) FERC Form 2. Washington, D.C. 
Fuss, M. N. (1994) "Productivity Growth in Canadian Telecommunications," The Canadian Journal of Economics, 27 (2): 371-392.

Gagne, R. and P. Ouellette (1998) "On the Choice of Functional Forms: Summary of a Monte Carlo Experiment,” Journal of Business \& Economics Statistics, 16 (1): 118-124.

Guilkey, R.K. C.A.K. Lovell, R.C. Sickles (1983) “A Comparison of Three Flexible Functional Forms,” International Economic Review, 24: 591-616.

Hall, R. and D.W. Jorgensen (1967) “Tax Policy and Investment Behaviour,” American Economic Review, 57: 391-414.

Hjalmarsson, L. and A. Veiderpass (1992) "Efficiency and Ownership in Swedish Electricity Retail Distribution,” Journal of Productivity Analysis, 3: 7-23.

Hollas, D. R. and R. S. Stanley (1994) "The Economic Efficiency of Public vs. Private Gas Distribution Utilities,” Annals of Public and Cooperative Economics, 65 (2): 281-300.

Hulten, C. and F. Wykoff (1981) “The Measurement of Economic Depreciation,” in C. Hulten (ed.), Depreciation, Inflation, and the Taxation of Income from Capital. Urban Institute: Washington D.C.

Jamasb, T. M. Pollitt (2001) "Benchmarking and Regulation: International Electricity Experience,” Utilities Policy, 9: 107-130.

Jamasb, T., Pollitt, M. International Benchmarking and Regulation: An Application to European Electricity Distribution Utilities. Energy Policy 2003; 31; 1609-1622.

Joskow, P.L. (2007) "Incentive Regulation in Theory and Practice: Electricity Distribution and Transmission Networks," Prepared for the National Bureau of Economic Research Regulation Project, http://www.nber.org/books_in_progress/econ-reg/joskow9-12-07.pdf (accessed July 2, 2009)

Kim, T.-Y. and J.-D. Lee (1995) "Cost Analysis of Gas Distribution Industry with Spatial Variables. Journal of Energy and Development,” 20 (2): 247-67.

Joskow, P.J. and R. Schmalensee (1986) “Incentive Regulation for Electric Utilities,” Yale Journal on Regulation, 4 (1); 1-49.

Kumbhakar, S.C. A. Lozano-Vivas (2005) "Deregulation and Productivity: The Case of Spanish Banks. Journal of Productivity Economics,” 27 (3): 331-351.

Laffont, J. and J. Tirole (1993) A Theory of Incentives in Regulation and Procurement. MIT Press: Cambridge, MA.

Lowry, M. N. and L. Kaufmann (2002) "Performance-Based Regulation of Utilities," Energy Law Journal, 23: 399-457.

Lowry, M. N. and L. Kaufmann (2006) "Alternative Regulation for North American Electric Utilities,” The Electricity Journal, 19 (5): 15-26. 
Lowry, M.N., L. Getachew D. Hovde (2005) "Econometric Benchmarking of Cost Performance: The Case of US Power Distributors,” The Energy Journal 26 (3): 75-92.

Magnus, J. R. (1978) "Maximum Likelihood Estimation of the GLS Model with Unknown Parameters in the Disturbance Covariance Matrix,” Journal of Econometrics, 7: 281-312.

Mullen, J. K. (2001) "Long-run Technical Change and Multifactor Productivity Growth in US Manufacturing,” Applied Economics, 33: 301-308.

Neuberg, L. (1977) "Two Issues in Municipal Ownership of Electric Power Distribution Systems,” Bell Journal of Economics, 8: 302-323.

Oberhofer, W. and J. Kmenta (1974) "A General Procedure for Obtaining Maximum Likelihood Estimates in Generalized Regression Models,” Econometrica 42: 579-90.

RS Means (1999) Heavy Construction Cost Data, 13th Annual Edition. Kingston, MA.

Salvanes, K. and S. Tjotta (1994) "Productivity Differences in Multiple Output Industries," Journal of Productivity Analysis, 4: 23-43.

Shleifer, A. (1985) “A Theory of Yardstick Competition,” Rand Journal of Economics, 16: 319-327.

Theil, H. (1965) “The Information Approach to Demand Analysis,” Econometrica, 33: 6787.

Törnqvist, L. (1936) “The Bank of Finland’s Consumption Price Index,” Bank of Finland Monthly Bulletin, 10: 1-8.

Whitman, Requardt, and Associates (1993) Handy-Whitman Index of Public Utility Construction Costs. Baltimore, MD.

Yatchew, A. (2001) "Incentive Regulation of Distributing Utilities Using Yardstick Competition,” The Electricity Journal, January/February: 56-60.

Zellner, A. (1962) "An Efficient Method of Estimating Seemingly Unrelated Regressions and Tests of Aggregation Bias," Journal of the American Statistical Association, 57: 34868. 